\title{
On the developing of the mathematical model of all-wheel drive vehicle
}

\author{
Andrey Efimov ${ }^{1}$, Sergey Kireev ${ }^{1}$, and Marina Korchagina ${ }^{1}$ \\ ${ }^{1}$ Don State Technical University, Rostov-on-Don, Russia
}

\begin{abstract}
The mathematical model of all-wheel-drive vehicle is proposed, which makes it possible to investigate the economic indicators of the vehicle's movement for choosing the optimal type of central differential in a given range of road conditions.
\end{abstract}

\section{Introduction}

At vehicle movement, there are two factors that specify conflicting requirements for transfer box drive and axle drive. Let's describe them: each wheel rotating at different speeds and reduced adherence of one or more wheels [1-10]. These factors tend to be of time-varying nature. The nature of the studied processes is transient; it will be influenced by the inertia, stiffness and damping properties of the vehicle power train parts. All this makes the task to solve the task by the dynamics methods.

\section{Main part}

To assess the applicability of drive of a particular type at designed or already existing vehicle, a mathematical model of all-wheel-drive vehicle was developed to determine the main force and kinematic parameters of movement under the specified road conditions.

In analytical studies, the vehicle is represented as a multimass dynamic system, where $J_{1}, J_{2}, J_{3}, J_{4}, J_{5}, J_{6}, J_{x z}$
- are the rotational inertia of the flywheel and the moving mass of engine, the rotational inertia of clutch parts, gearbox and transfer case reduced to the carrier of the central differential, the rotational inertia of sun gear and ring gear and reduced parts, the rotational inertia of front and rear wheels, the rotational inertia of vehicle frame in the $x z$-plane with respect to the center of mass; $m$ - vehicle mass. In the dynamic system, in addition to the drive circuit, the changes in soil reactions to the wheels, the stiffness and damping properties of the transmission parts, and the spin of the drive wheels are taken into account.

At the development of the mathematical model, the following assumptions are made: the frame of the machine is a solid body with a longitudinal axis of symmetry; through-the-thickness slip of the tires of the driving wheels is neglected; frictional forces in the transmission element are considered to be zero; assume the conditions for the adherence of the right and left wheels of the same bridge to be the same.

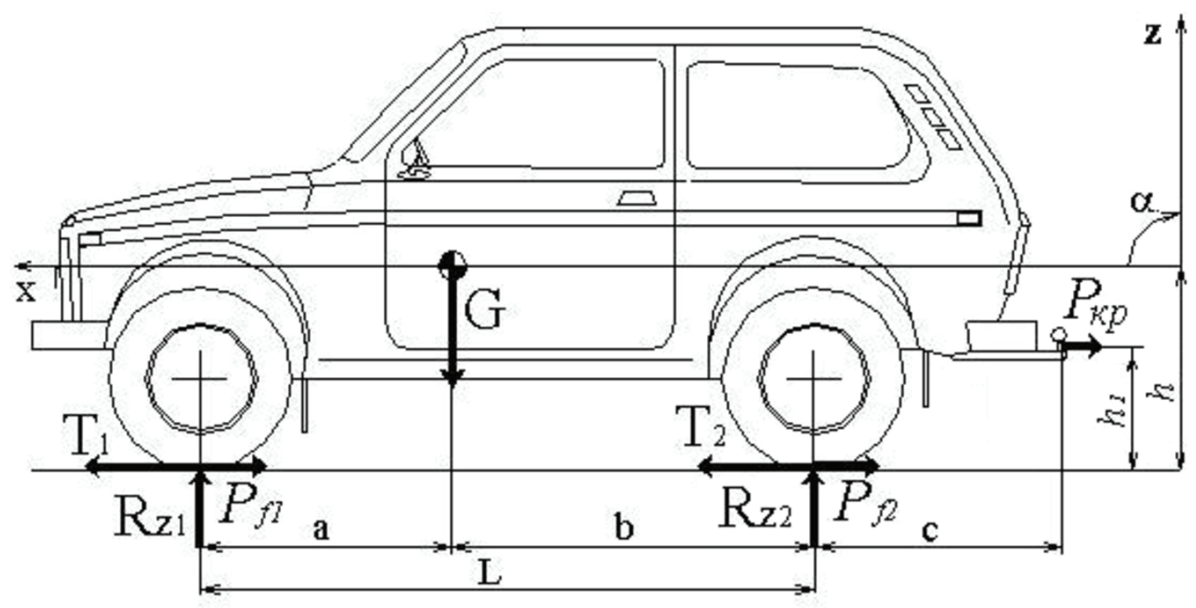

Fig. 1. Scheme of forces acting on the vehicle

\footnotetext{
* Corresponding author: efimovav2007@yandex.ru
} 
Figure 2 shows the dynamic model of a wheeled vehicle with a differential transfer box drive,

Figure 1 shows the forces acting on the wheeled vehicle, where $T_{1}, T_{2}$ - tractive effort of front and rear wheels; $P_{f l}, P_{f 2}$ - power of rolling resistance of front and rear wheels respectively; $R_{Z 1}, R_{Z 2}$ - vertical soil reactions to front and rear wheels respectively; $P_{h}$ - hook power; $G-$ vehicle gravity; $a, b, L, h, h_{1}$-geometric dimensions of the vehicle.

where $M_{e}$ - engine torque; $M \varphi$ - torque of clutch friction; $M_{\varphi 1}, M_{\varphi 2}$ - torques on the wheels from traction forces, $M_{\varphi 1}=T_{1} r_{w 1}, M_{\varphi 2}=T_{1} r_{w 2} ; r_{w 1}, r_{w 2}-$ dynamic radius of front and rear drive wheels; $i_{12}, i_{35}, i_{46}$, $c_{12}, c_{35}, c_{46}, k_{12}, k_{35}, k_{46}-$ transmission ratios, coefficient of stiffness and damping coefficients of power train sections between first and second, third and fifth, fourth and sixths mass respectively; $c_{\chi 1}, c_{\chi^{2}}$, $k_{\chi_{1}}, k_{\chi^{2}}-$ extension rigidity and pitch damping coefficient of tires of front and rear wheels respectively; $i_{\mathrm{d}}-$ transmission ratio of differential,

$$
i_{\mathrm{d}}=\left.\frac{\omega_{3}}{\omega_{4}}\right|_{a t \omega_{2}=0} .
$$

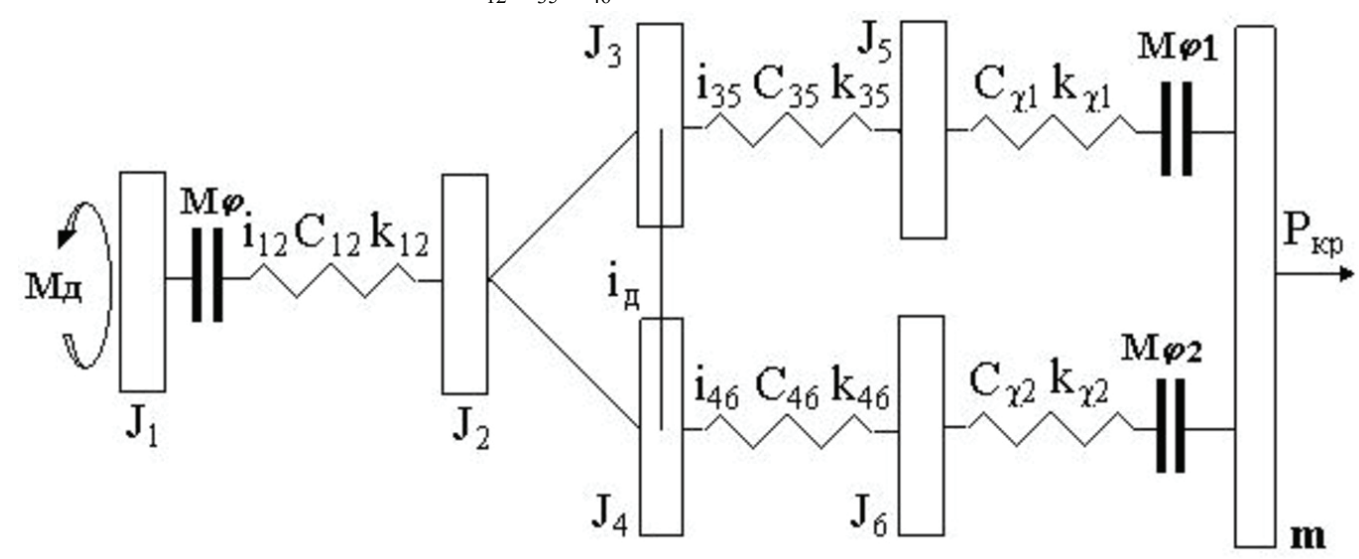

Fig. 2. Diagram of dynamic model of transmission with differential transfer box drive

Since $\omega_{3}$ and $\omega_{4}$ at stopped carrier $\left(\omega_{2}=0\right)$ are oppositely directed for all epicyclic gears used as differential, then $i_{\mathrm{d}}<0$, which explains the change of direction of torque $\mathrm{M}_{46}$ after its reduction (see Figure 3).

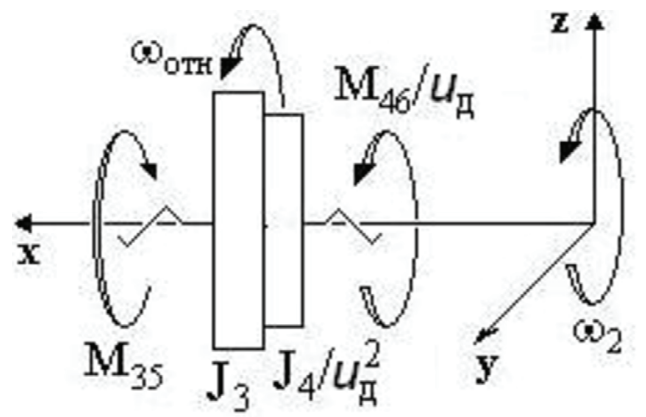

Fig. 3. Diagram of the dynamic model of the transmission section with a differential transfer box drive involved in the relative motion

Besides, $\left|i_{\mathrm{d}}\right|=u_{\mathrm{d}} \cdot u_{d}-$ transmission number of central differential.

The above configuration of the dynamic model of a vehicle with a differential drive is the most general case. Other types of drive can be described using the same model with some refinements.

The mathematical model of a wheeled vehicle equipped with a differential drive is represented as a system of differential equations:

$$
\left\{\begin{array}{l}
J_{1} \ddot{\varphi}_{1}=M_{\mathrm{ea}}-\frac{M_{12}}{i_{12}} ; \\
\left(J_{2}+J_{3}+J_{4}\right) \ddot{\varphi}_{2}=M_{12}-\frac{M_{35}}{i_{35}}-\frac{M_{46}}{i_{46}} ; \\
J_{5} \ddot{\varphi}_{5}=M_{35}-T_{1} r_{K 1} ; \\
J_{6} \ddot{\varphi}_{6}=M_{46}-T_{2} r_{K 2} ; \\
\left(\begin{array}{l}
\left.J_{3}+\frac{J_{4}}{u_{d}^{2}}\right) \ddot{\varphi}_{r e l}=\frac{M_{46}}{u_{\mathrm{d}} i_{46}}-\frac{M_{35}}{i_{35}} ; \\
m \ddot{x}=T_{1}+T_{2}-P_{f_{1}}-P_{f 2}-P_{K P} ; \\
J_{X Z} \ddot{\alpha}=R_{Z 1} a-R_{Z 2} b+ \\
+\left(T_{1}+T_{2}-P_{f 1}-P_{f 2}\right) h-P_{K P}\left(h-h_{1}\right) ; \\
m \ddot{z}=R_{Z 1}+R_{Z 2}-G
\end{array}\right.
\end{array}\right.
$$

For all-wheel-drive vehicle the following generalized coordinates are taken:

$x, z$ - respectively horizontal and vertical movement of vehicle frame; $\varphi_{1}, \varphi_{2}, \varphi_{5}, \varphi_{6}, \varphi_{\text {rel }}$ - angular coordinates of the flywheel of the engine, carrier of central differential, front and rare wheels and rotation angle of sun gear of central differential against carrier; $\alpha$ - the angle of rotation of the vehicle frame around a horizontal axis passing through the center of mass.

The system of differential equations is supplemented by the equations of non-holonomic constraints [11]

\footnotetext{
*Corresponding author: efimovav2007@yandex.ru
} 


$$
\begin{aligned}
& \dot{\chi}_{1}=r_{w 1} \dot{\phi}_{5}-\dot{x}-\left(\lambda_{1}+k_{\delta 1}\right) \dot{\phi}_{5} T_{1} ; \\
& \dot{\chi}_{2}=r_{w 2} \dot{\phi}_{6}-\dot{x}-\left(\lambda_{2}+k_{\delta 2}\right) \dot{\phi}_{6} T_{2},
\end{aligned}
$$

where $\chi_{1}, \chi_{2}$ - longitudinal deformation of tires of driving wheels; $\lambda_{1}, \lambda_{2}$ - coefficients of tire elastic tangency; $k_{\delta}$ - coefficient of specific slip of the spinning driving wheel.

Consider the analytic dependence of the main parameters included in the system of differential equations (1).

The equation that defines the dependence of power on rate speed at a constant position of the throttle body, for gasoline engines, in accordance with [12] is as follows:

$$
N_{e x}=N_{e} \frac{n_{x}}{n_{N}}\left(1+\frac{n_{x}}{n_{N}}-\left(\frac{n_{x}}{n_{N}}\right)^{2}\right),
$$

where $N_{e}, n_{N}$ - nominal (maximum) rating power $(\mathrm{kW})$ and corresponding rate speed of engine crankshaft $(\mathrm{r} / \mathrm{m})$ for this position of throttle shutter.

Let's use this formula to determine engine torque when the throttle shutter is not fully open. According to [12], torque of engine $(\mathrm{N} \cdot \mathrm{m})$ is defined as:

$$
M_{\mathrm{e}}=3 * 10^{4} N_{e x} /\left(\pi n_{x}\right) .
$$

Angular velocity and shaft speed are related by the formula:

$$
n=\frac{30}{\pi} \omega
$$

Therefore,

$$
M_{\mathrm{e}}=\frac{N_{e}}{\omega_{N}}\left(1+\frac{\omega}{\omega_{N}}-\left(\frac{\omega}{\omega_{N}}\right)^{2}\right),
$$

where $N_{e}, \omega_{N}$ - maximum rating power (W) and corresponding angular velocity of engine crankshaft $(\mathrm{r} / \mathrm{m})$ when the throttle shutter is partially open, $N_{e}=k_{N} N_{e}^{\max }$,

where $N_{e}^{\max }$ - maximum rating power (W) when the throttle shutter is fully open;

$k_{N}$ - power filling factor of engine (corresponds to a certain rate of opening of throttle shutter).

Based on the assumption of a linear relationship between $\omega_{N}$ and $N_{e}$,

$$
\omega_{N}=\left(\omega_{N}^{\max }-\omega_{x x}\right) k_{N}+\omega_{x x},
$$

where $\omega_{N}^{\text {мax }}$ - angular velocity of engine crankshaft corresponding to the maximum engine power when the throttle shutter is fully open $N_{e}^{\text {мах }} ; \omega_{x x}$ - angular velocity at no-load.

Acceleration of the vehicle is carried out under unsteady operating conditions of the engine. According to [13], torque developed by the engine during acceleration is

$$
M_{e a}=M_{\mathrm{e}}\left(1-\gamma \frac{d \omega}{d t}\right)
$$

where $\gamma$-coefficient taking into account the decrease of torque developed by the engine due to the transient operation mode, $\gamma=0,07-0,09$.

Torques acting in the system between the corresponding masses:

$$
\begin{aligned}
& M_{12}=c_{12}\left(\frac{\phi_{1}}{i_{12}}-\phi_{2}\right)+k_{12}\left(\frac{\dot{\phi}_{1}}{i_{12}}-\dot{\phi}_{2}\right) ; \\
& M_{35}=c_{35}\left(\frac{\phi_{3}}{i_{35}}-\phi_{5}\right)+k_{35}\left(\frac{\dot{\phi}_{3}}{i_{35}}-\dot{\phi}_{5}\right) ; \\
& M_{46}=c_{46}\left(\frac{\phi_{4}}{i_{46}}-\phi_{6}\right)+k_{46}\left(\frac{\dot{\phi}_{4}}{i_{46}}-\dot{\phi}_{6}\right),
\end{aligned}
$$

where angle of rotation and speed of sun gear and ring gear of differential are expressed through the accepted generalized coordinates,

$$
\begin{aligned}
& \varphi_{3}=\varphi_{2}+\varphi_{r e l} ; \\
& \varphi_{4}=\varphi_{2}-\frac{\varphi_{r e l}}{u_{d}} ; \\
& \dot{\varphi}_{3}=\dot{\varphi}_{2}+\dot{\varphi}_{r e l} ; \\
& \dot{\varphi}_{4}=\dot{\varphi}_{2}-\frac{\dot{\varphi}_{r e l}}{u_{d}} .
\end{aligned}
$$

With locking differential, the relative motion of the differential is not possible, so the movement of a vehicle with a similar type of drive is described by a single dynamic model, the circuit of which is shown in Figure 4. The mathematical model of a vehicle with locking differential is described by the system of differential equations (1), supplemented by the condition:

$$
\left\{\begin{array}{l}
\varphi_{r e l}=0 \\
\dot{\varphi}_{r e l}=0 \\
\ddot{\varphi}_{r e l}=0
\end{array}\right.
$$

Friction torque of the clutch $M_{\Phi}$, according to [14]:

$$
M_{\Phi}=\mu Q_{s p} r_{f} i
$$

where $\mu$ - coefficient of friction; $i$ - number of friction pairs; $r_{f}$ - friction radius; $Q_{s p}$ - force of pressure springs;

$$
Q_{s p}=\left\{\begin{array}{l}
Q_{s p}^{\max } \frac{t}{t_{o n}}, \quad \text { at } t \leq t_{o n} \\
Q_{s p P}^{\max }, \quad \text { at } t>t_{o n},
\end{array}\right.
$$

where $Q_{s p}^{\max }$ - maximum effort of pressing spring; $t_{o n}-$ clutch on-time. 


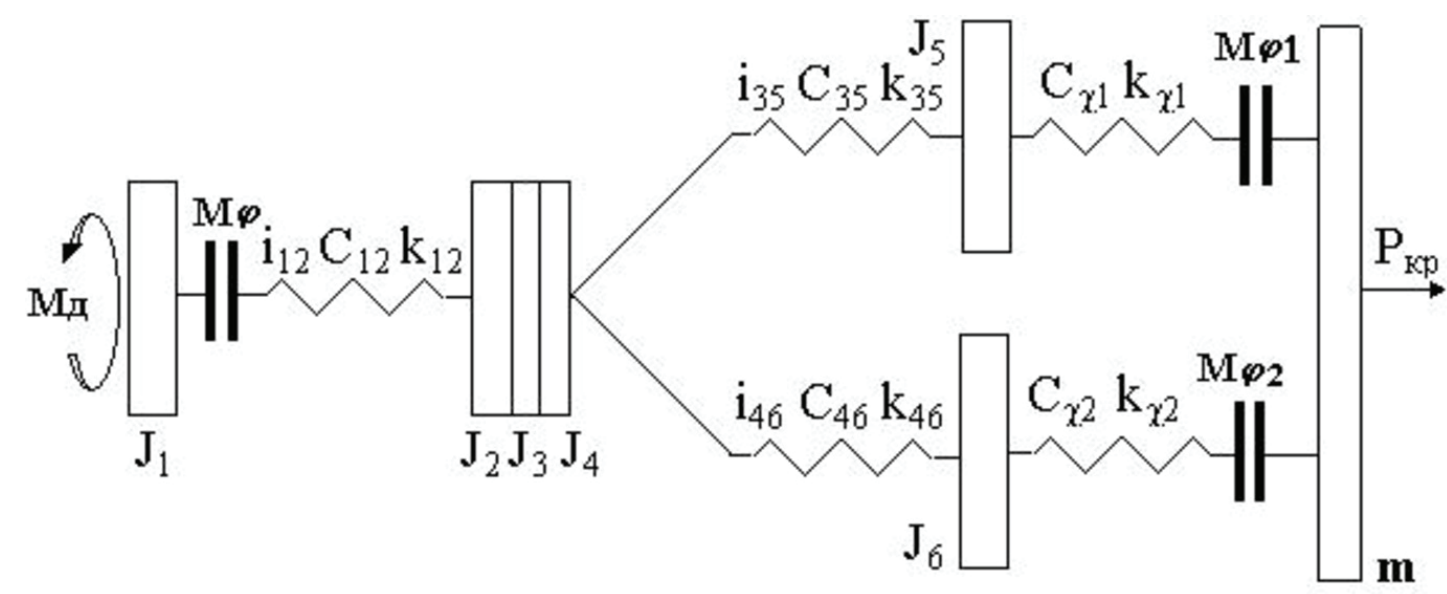

Fig. 4. Diagram of a dynamic transmission model without taking into account the relative motion in central differential drive

The frictional moment of $M_{\phi}$ clutch restricts the torque between the engine and $M_{12}$ transmission.

Tangent traction force of the drive wheel, according to $[11]$,

$$
T=c_{\chi} \chi+k_{\chi} \dot{\chi}
$$

where $c_{\chi}, k_{\chi}$ - longitudinal stiffness and coefficient of longitudinal damping of the tire of the corresponding wheel; $\chi$ - longitudinal deformation of tires of driving wheels.

Coefficient of specific spin by [11]

$$
k_{\delta}=r_{w} \delta / T
$$

where $T$ - total tractive effort of the wheels of this axle; $r_{\mathrm{w}}$ - axle wheels radius; $\delta$ - axle wheels spin. The spins of left and right wheels are equal. Consider their clutching conditions to be the same (see assumptions adopted in the mathematical model).

In accordance with [13], the tangential traction force of the wheel is calculated by the formula:

$$
T=R_{Z} \phi_{a d h}\left(1-e^{-K|\delta|}\right) \operatorname{sign}\left(V_{T}-V_{a c t}\right),
$$

where $T-$ tangential force of wheel traction; $R_{Z}$ - vertical soil reaction to wheel; $\varphi_{a d h}$ - coefficient of wheel adherence with soil; $K$ - empirical coefficient; $V_{T}$ - theoretical wheel speed; $V_{a c t}-$ actual vehicle speed.

From here, we express spin through tractive effort:

$$
\delta=-\frac{1}{K} \ln \left(1-\frac{|T|}{\varphi_{\text {adh }} R_{Z}}\right) \operatorname{sign}(T),
$$

The formula (9) is valid in the range of values $\delta=-1 \ldots 1$.

Vertical reaction to front and rear wheels

$$
\begin{aligned}
& R_{Z 1}=G_{1}-C_{1}(z+\alpha a)-K_{1}(\dot{z}+\dot{\alpha} a) \\
& R_{Z 2}=G_{2}-C_{2}(z-\alpha b)-K_{2}(\dot{z}-\dot{\alpha} b),
\end{aligned}
$$

where $G_{1}, G_{2}$ - vehicle weight in statics falling on the front and rear wheels; $C_{1}, C_{2}-$ radial stiffness of tires and suspension of front and rear wheels; $K_{l}, K_{2}-$ coefficient of damping of tires and suspension of front and rear wheels.

Effort of resistance of front and rear wheels' rolling

$$
\begin{aligned}
& P_{f 1}=f R_{Z 1} ; \\
& P_{f 2}=f R_{Z 2},
\end{aligned}
$$

where $f$-rolling resistance coefficient, [15-18].

\section{Conclusion}

The solution of the system of equations (1) together with the analytic relations (2) - (11) can be carried out by the Runge-Kutta method [19-21]. Comparison of the calculated data with the experimental data has shown the adequacy of the mathematical model obtained. It allows carrying out further studies of the effect of the drive type on the spin efficiency of wheeled vehicle using computational methods, which has a number of advantages. As follows from the analysis of the results of theoretical studies, the following conclusions can be drawn:

1. The developed dynamic model of the vehicle is distinguished by a certain novelty and reflects the behavior of all links in the dynamic system.

2. The mathematical model developed in accordance with the dynamic model allows modeling the movement of a vehicle equipped with a differential, blocked, or differential drive with a limited gear ratio in a variety of road conditions and can be used for comparative analysis of vehicle spin losses equipped with different types of drive.

\section{References}

1. P. V. Aksenov, Multi-axle cars (Mechanical Engineering, Moscow, 1989)

2. A.V. Andreev, V.V. Vancevich, A.Kh. Lefarov, Differential Wheeled, Machines, Mechanical Engineering, 1987.

\footnotetext{
* Corresponding author: efimovav2007@yandex.ru
} 
3. A. Yu. Barykin, Automobile industry, 9 (2004).

4. V.V. Vancevich, D.A. Dubovik, A.F. Andreev, V.I. Kabanov, V.G. Ermalenok, V.S. Voiteshonok, Automobile industry, 2 (2006).

5. A.V. Keller, G.D. Dragunov, Automotive industry, 1 (2004)

6. G.V. Novikov, V.V. Pogorelov, G.B. Shipilevsky, Automotive industry, 8 (2007).

7. I.V. Grinchenko, Investigation of the loading of transmissions of a multi-drive car while driving along a curvilinear trajectory, Diss. PhD. Moscow, (1976)

8. A.Kh. Lefarov, M.S. Vysotsky, V.V. Vantsevich, V.I. Kabanov, Energy loading and reliability of differential mechanisms of transport-traction machines, (Navuka i tehnika, Minsk, 1991)

9. B.M. Tverskov, Automotive industry, 3 (1998)

10. E.A. Chudakov, Circulation of parasitic power in the mechanisms of a non-differential car (Mashgiz, Moscow, 1950)

11. V.P. Tarasik, Tractors and agricultural machinery, 4 (1981)

12. A.I. Kolchin, V.P. Demidov, Calculation of automobile and tractor engines: Guide for universities, (Vysshaya shkola, Moscow, 2008)

13. A.I. Grishkevich, L.A. Moliboshko, O.S. Rukteshel, V.M. Belyaev, The use of computers in the design and calculation of vehicle, (1978)

14. I.P. Ksenevich, A.S. Solonsky, V.Ya. Rubenchik, L.I. Peskina, Tractors and agricultural machinery, 5 (1979).

15. A.A. Polungyan, Design of all-wheel drive vehicles, 1, (Bauman University Publishing House, Moscow, 2008)

16. J. Mackerle, Modern economical car, Ed. A.R. Benedictova, (Mechanical Engineering, Moscow, 1987)

17. A. Sh. Khusainov, Operational properties of the car, (UlSTU, Ulyanovsk, 2011).

18. V.F. Platonov, Mechanical Engineering, 1989.

19. B.P. Demidovich, I.A. Maron, E.Z. Shuvalova Numerical methods of analysis (Fizmatgiz, Moscow, 1963)

20. N.S. Bakhvalov, N.P. Zhidkov, G.M. Kobelkov Numerical methods (Laboratory of Basic Knowledge, Moscow, 2001)

21. V.A. Il'ina, P.K. Silaev Numerical methods for theoretical physicists. Part 2, (Institute for Computer Research, Moscow-Izhevsk, 2004) 